\title{
$\mathrm{CFEM}$ 을 이용한 구속조건이 있는 다물체 운동해석 프로그램 개발
}

박선호*, 이승수**

\section{Development of Multi-body Dynamics Analysis Program with Constraints using CFEM}

Sunho Park* and Seungsoo Lee**

\begin{abstract}
In this study, Constraint Force Equation Methodology (CFEM) is used to develop a multi-body dynamic analysis program with constraints. Seven constraint models are implemented to analyze constraint motions of multiple bodies. The augmented equations with the constraints are solved with the 4th order Runge-Kutta method for higher degree of accuracy. The analysis code is verified by comparing the analysis results of the motion of bodies with various constraints to published results.
\end{abstract}

\section{초 록}

본 연구에서는 CFEM을 이용하여 구속조건이 있는 다물체의 운동방정식해석 프로그램을 개발하였다. 다양한 구속조건을 다루기 위하여 7 개의 구속모델이 적용되었다. 구속조건으로 보안된 운동방정식은 높은 정확도를 위해 4 차의 Runge-Kutta 방법을 사용하여 해석하였다. 다양한 구속조건이 있는 문제에 대하여 개발된 프로그램을 적용하고, 발표된 결과와 비교 함으로써 개발 프로그램을 검증하였다.

Key Words : CFEM(Constraint Force Equation Methodology), Constraints(구속조건), Multi-body Dynamics(다물체 동역학)

\section{I. 서 론}

항공기로부터 분리되는 외부장착물의 안전한 분리는 외부장착물 목적의 달성을 위해서는 필수 적이다. 또한 외부장착물 분리의 안전성은 항공 기와 조종사의 안전과 직접 연관되기에 비행시험 전에 해석적으로 확인하여야 한다. 외부장착물의 안전한 분리를 위하여 사출장치(ejector)를 사용 하기도 하고, 내부 무장이나 익단(wing tip)에 장

† 2011년 5월 11일 접수 2012년 1월 26일 심사완료

* 정회원, 인하대학교 대학원 항공우주공학과

** 정회원, 인하대학교 기계공학부 항공우주공학전공 교신저자, E-mail : slee@inha.ac.kr 인천광역시 남구 용현동 253
착된 무장들은 회전조인트(hinge or revolute joint)나 레일발사대(rail launch)를 통해 분리되기 도 한다 $[1,2]$. 이러한 경우 분리 운동해석을 위 해서는 구속조건이 있는 운동방정식의 해석이 필 요로 하게 된다. 구속조건이 있는 운동방정식 해 석은 날개전개를 동반한 외부장착물의 분리 해석 에도 사용될 수 있다[3]. 그러므로 다양한 종류의 외부장착물 분리해석을 위해서는 구속조건이 있 는 운동방정식을 해석할 수 있는 프로그램의 개 발이 필수적이다[4].

본 논문에서는 $\mathrm{CFEM}$ (Constraint Force Equation Methodology) $[5,6]$ 가 적용되어 다양한 구속조건 있는 다물체 동역학문제를 해석할 수 있는 프로 그램을 개발하였다. CFEM은 구속력과 구속모멘 트를 이용하여 다물체를 연결하는 다양한 자유도 
(Degree of Freedom)을 갖는 조인트로 모델링하 는 다물체 운동해석 방법이다. CFEM은 조인트 를 각각의 물체에 적용하여 물체의 개수에 상관 없이 적용할 수 있다. 본 논문에서 기술한 조인 트는 고정조인트(fixed joint), 회전조인트(hinge or revolute joint), 만능조인트(universal joint), 구면조인트(ball joint), 병진조인트(slider joint), 평면조인트(planar joint), 원통조인트(cylindrical joint)의 7 개이다. 개발될 프로그램을 이용하여 고정조인트와 회전조인트로 모델이 가능한 다물 체의 운동을 해석하고, 이를 참고문헌[2, 4]과 상 용프로그램인 Universal Mechanism[7]의 결과와 비교함으로써 개발된 프로그램을 검증하였다. 나 머지 조인트에 대한 검증은 참고문헌[8]에 자세 히 기술되어 있다. 마지막으로 회전조인트로 모 델링하여 해석할 수 있는 무장분리에 대해서 공 기력을 무시한 상태에서 해석하였다[9].

\section{Constraint Force Equation Methodology}

\section{1 운동방정식}

Figure 1 과 같이 한 개의 조인트에 의해서 연 결되어져 있는 두 강체(rigid body)의 운동에 대 하여 살펴보자. $F_{A}^{(E X T)}$ 와 $F_{B}^{(E X T)}$ 은 각각 물체에 작용하는 중력과 공기력, 추력 등 외력의 합이고, $T_{A}^{(E X T)}$ 과 $T_{B}^{(E X T)}$ 는 각 물체 무게중심에 작용하는 모멘트의 합이다. 그리고 두 물체의 연결점에서 는 구속력, $F^{(C O N)}$ 과 구속모멘트, $T^{(C O N)}$ 가 작용 한다. 구속력와 구속모멘트를 고려하면, 두 물체 에 대한 자유물체도(free-body diagram)는 Fig. 1 과 같다. 물론 구속력과 구속모멘트는 구속조건 이 만족될 수 있도록 구해져야 한다.

물체 $\mathrm{A}$ 의 선형운동량 보존법칙은 관성좌표계 (inertial coordinate)로 나타내면 다음과 같다.

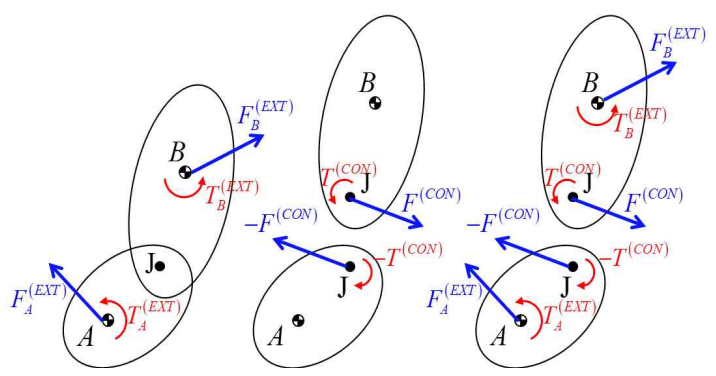

Fig. 1. Free Body Diagram of multi-body

$$
m_{A} \dot{\overrightarrow{V_{A}}}=\overrightarrow{F_{A}}(E X T)+\overrightarrow{F_{A}}(C O N)
$$

각 운동량 보존법칙은 다음과 같다.

$$
\begin{aligned}
& I_{A} \overrightarrow{\overrightarrow{\omega_{A}}}+\overrightarrow{\omega_{A}} \times I_{A} \overrightarrow{\omega_{A}} \\
& \quad=\overrightarrow{T_{A}}(E X T)+\overrightarrow{\rho_{A}} \times \overrightarrow{F_{A}}(C O N)+\overrightarrow{T_{A}}(C O N)
\end{aligned}
$$

물체 $\mathrm{B}$ 의 선형 및 각 운동량 보존법칙은 다음과 같다.

$$
\begin{aligned}
& m_{B} \dot{\overrightarrow{V_{B}}}=\overrightarrow{F_{B}}(E X T)+\overrightarrow{F_{B}}(C O N) \\
& I_{B} \overrightarrow{\overrightarrow{\omega_{B}}}+\overrightarrow{\omega_{B}} \times I_{B} \overrightarrow{\overrightarrow{\omega_{B}}} \\
& =\overrightarrow{T_{B}}(E X T)+\overrightarrow{\rho_{B}} \times \overrightarrow{F_{B}}(C O N)+\overrightarrow{T_{B}}(C O N)
\end{aligned}
$$

이때 식(2)와 (4)식에서 $\overrightarrow{\rho_{A}}$ 와 $\overrightarrow{\rho_{B}}$ 는 각각 물체 $\mathrm{A}$ 와 $\mathrm{B}$ 의 무게중심에서 접촉점까지의 거리이다. 만 약 구속이 없는 운동을 하게 된다면, 구속력과 구 속모멘트는 0으로 놓을 수 있다. 그러면, 식(1) (4) 는 2 개의 독립된 강체의 운동방정식이 된다.

\section{2 운동학적 관계식}

물체의 속도, $\vec{V}$ 는 무게중심의 위치 벡터, $\vec{R}$ 의 시간미분으로 나타낼 수 있다.

$$
\overrightarrow{\vec{R}}=\vec{V}
$$

몸체축에 대한 각속도, $\vec{\omega}=\hat{i} P+\hat{j} Q+\hat{k} R$ 는 오일 러각(Euler angle)의 시간미분으로 다음의 식(6) 과 같이 나타낼 수 있다.

$$
\begin{gathered}
\dot{\Phi}=P+Q \sin \Phi \tan \Theta+R \cos \Phi \tan \Theta \\
\dot{\Theta}=Q \cos \Phi-R \sin \Phi \\
\dot{\Psi}=Q \frac{\sin \Phi}{\cos \Theta}+R \frac{\cos \Phi}{\cos \Theta}
\end{gathered}
$$

이를 행렬식으로 나타내면 다음과 같다.

$$
\dot{\vec{E}}=\gamma \vec{\omega}
$$

여기에서 $E$ 와 $\gamma$ 는 다음과 같이 정의된다.

$$
E=\left[\begin{array}{c}
\Phi \\
\Theta \\
\Psi
\end{array}\right], \gamma=\left[\begin{array}{ccc}
1 & \sin \phi \tan \theta & \cos \phi \tan \theta \\
0 & \cos \phi & -\sin \phi \\
0 & \frac{\sin \phi}{\cos \theta} & \frac{\cos \phi}{\cos \theta}
\end{array}\right]
$$

\section{3 작용·반작용법 칙}

물체 $\mathrm{A}$ 와 $\mathrm{B}$ 의 구속력은 작용·반작용 법칙에 의해서 다음과 같은 관계가 성립한다. 


$$
\begin{aligned}
\overrightarrow{F_{A}}(C O N) & +\overrightarrow{F_{B}}(C O N)=0 \\
{\overrightarrow{T_{A}}}^{(C O N)} & +\overrightarrow{\vec{T}_{B}}(C O N) \\
& +\left(\overrightarrow{r_{B}}-\overrightarrow{r_{A}}\right) \times \overrightarrow{F_{B}}(C O N)=0
\end{aligned}
$$

여기에서 $\vec{r}$ 는 관성좌표계에서 두 물체가 접촉하 는 점까지의 위치 벡터이고, $\vec{R}$ 은 무게중심의 위 치 벡터이다. 즉, $\vec{r}=\vec{R}+\vec{\rho}$ 이다.

\section{4 구속방정식}

식(9), (10)을 살펴보면, 식(1) (4), (5) 및 (7)의 미지수는 물체 $\mathrm{A}$ 와 $\mathrm{B}$ 의 $x, y, z$ 방향 무게중심 위치, 속도, 각속도, 구속력, 구속모멘트 등 30개 이다. 방정식의 갯수은 (1) (4), (5) 및 (7)의 24개 에 불과하다. 그러나, 두 물체 사이의 구속조건을 활용하면 부족한 방정식을 얻을 수 있다. 구속방 정식은 조인트에 따라 다음 네 개의 구속식을 적 절히 조합하여 구할 수 있다.

첫째 식은 물체 $\mathrm{A}$ 에서 정의된 단위 벡터 $\widehat{e_{A}}$ 방 향으로 물체 $\mathrm{B}$ 의 움직임이 구속되는 병진구속식 이다.

$$
\left(\overrightarrow{R_{A}}+\overrightarrow{\rho_{A}}-\overrightarrow{R_{B}}-\overrightarrow{\rho_{B}}\right) \cdot \widehat{e_{A}}=0
$$

둘째 식은 두 물체에서 정의된 두 단위벡터 $\widehat{e_{A}}$, $\widehat{e_{B}}$ 가 일정한 각도를 이루도로 물체 $\mathrm{B}$ 의 움직임 이 구속되는 회전구속식이다.

$$
\widehat{e_{B}} \cdot \hat{e_{A}}=\cos \lambda_{A B}
$$

여기에서 $\lambda_{A B}$ 는 두 단위 벡터사이의 사잇각이다. 셋째 식은 특정 회전축으로 회전만이 가능한 구 속조건이 적용된 경우, 회전운동이 일어나는 축 에 대하여 마찰이 무시되면 구속모멘트가 0된다 는 조건식이다.

$$
\widehat{e_{A}} \cdot \vec{T}^{(C O N)}=0
$$

마지막으로 넷째 식은 특정방향의 병진운동만이 가능한 구속조건인 경우, 마찰이 무시되면 그 방 향으로의 구속력이 0 된다는 조건식이다.

$$
\widehat{e_{A}} \cdot \vec{F}^{(C O N)}=0
$$

위 4 가지 조건식을 조합하면 여러 가지 조인트를 모델링할 수 있다. 본 연구에서 개발한 프로그램 에는 Table 1 과 같이 7 가지 조인트가 적용되었다.
Table 1. Constraints and Degree of Freedom

\begin{tabular}{c|c|c}
\hline Joint type & $\begin{array}{c}\text { Translational } \\
\text { DOF }\end{array}$ & $\begin{array}{c}\text { Rotational } \\
\text { DOF }\end{array}$ \\
\hline Fixed & 0 & 0 \\
Hinge & 0 & 1 \\
Universal & 0 & 2 \\
Ball & 0 & 3 \\
Slider & 1 & 0 \\
Planar & 2 & 1 \\
Cylindrical & 1 & 1 \\
\hline
\end{tabular}

\subsection{Baumgarte 안정화 기법}

식(11) (14)의 구속방정식 다음과 같이 두 번 미분하여 적용한다.

$$
f=\ddot{g}=0
$$

그러나 식 (15)를 적용하면 수치적 불안정성에 의하여 시간이 지남에 따라 구속조건이 만족되지 않게 되는 경우가 발생한다. 구속조건을 더 정확 히 적용하기 위하여 Baumgarte 안정화 기법을 적용하였다. 이 방법에서는 구속방정식을 다음과 같이 변형하여 사용한다.

$$
f=\ddot{g}+2 \eta \dot{g}+\eta^{2} g=0
$$

이때 $\eta$ 는 사용자 입력변수로 문제에 따라 경험 적으로 구한다.

\section{6 시간 적분 방법}

운동방정식 (1) (4), 운동학적 관계식 (5), (7) 그리고 구속방정식 (16)을 정리하면 다음과 같은 형태의 대수방정식으로 쓸 수 있다.

$$
A x=b
$$

여기에서 $x$ 는 물체의 상태변수와 구속력 및 구 속모멘트로 구성된 변수이다. 예를 들면 두 개의 물체와 1 개의 조인트로 구성된 경우 $x$ 는 24 개의 상태 변수와 6 개의 구속력과 구속모멘트로 구성 되어 있다. 이로부터 24 개의 1차 미분방정식과 구속력과 구속모멘트에 관한 6개의 대수방정식을 얻을 수 있다. 24 개의 1 차 미분방정식은 4 차 Runge-Kutta 방법으로 시간 적분하였다. 4차 Runge-Kutta 방법은 4 차의 시간이산화 오차를 갖고 있어 Euler 방법보다 상대적으로 큰 시간간 격으로도 정확한 궤적을 구할 수 있다. 이 미분 방정식을 다음과 같이 쓸 수 있다. 


$$
\dot{y}=h(t, y)
$$

4th order Runge-Kutta방법은 다음과 같다.

$$
y^{n+1}=y^{n}+\frac{1}{6}\left(k_{1}+2 k_{2}+2 k_{3}+k_{4}\right)
$$

여기에서

$$
\begin{aligned}
& k_{1}=\Delta t h\left(t^{n}, y^{n}\right) \\
& k_{2}=\Delta t h\left(t^{n}+\frac{\Delta t}{2}, y^{n}+\frac{k_{1}}{2}\right) \\
& k_{3}=\Delta t h\left(t^{n}+\frac{\Delta t}{2}, y^{n}+\frac{k_{2}}{2}\right) \\
& k_{4}=\Delta t h\left(t^{n}+\Delta t, y^{n}+k_{3}\right) \\
& \text { III. 계산 결과 }
\end{aligned}
$$

\section{1 고정조인트}

Figure 2에는 고정조인트로 고정되어 있는 물 체 $\mathrm{A}$ 와 $\mathrm{B}$ 를 도시하였다. 고정된 두 물체는 선속 도가 없이 두 물체의 무게중심, $S^{*}$ 을 중심으로 각속도 $63.02 \hat{i}-82.32 \hat{j}+80.25 \hat{k}\left({ }^{\circ} / s\right)$ 로 회전하다 가 10 초 후 두 물체가 분리되어 각각 구속이 없 는 운동을 한다. 물체에 초기 위치는 두 물체의 무게중심을 관성좌표계의 원점으로 하고, $x$ 축과 일치하도록 하였다. 물체에 작용하는 중력 및 외 력은 없다고 가정하였다.

Figure 3과 4 에는 물체 $\mathrm{A}$ 와 $\mathrm{B}$ 의 각속도를 나타 내었다. 10 초까지 두 물체의 각속도는 동일하고 10 초 후에 달라진다. 이로 인해서 두 물체는 10 초 까지 고정조인트에 의해서 구속되어져 동일한 회 전을 하는 운동을 하는 것을 알 수 있다. 물체 B 의 관성모멘트가 물체 $\mathrm{A}$ 에 비해 매우 작아 분리

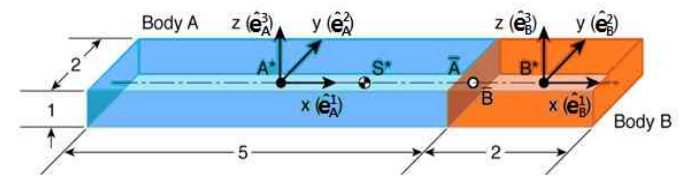

Fig. 2. Fixed joint

Table 2. Mass Property of Body A and B

\begin{tabular}{c|c|c}
\hline & Body A & Body B \\
\hline 질량 & $1.0 \mathrm{~kg}$ & $0.4 \mathrm{~kg}$ \\
$I_{x x}$ & $0.42 \mathrm{~kg} \mathrm{~m}^{2}$ & $0.17 \mathrm{~kg} \mathrm{~m}^{2}$ \\
$I_{y y}$ & $2.17 \mathrm{~kg} \mathrm{~m}^{2}$ & $0.17 \mathrm{~kg} \mathrm{~m}^{2}$ \\
$I_{z z}$ & $2.42 \mathrm{~kg} \mathrm{~m}^{2}$ & $0.27 \mathrm{~kg} \mathrm{~m}^{2}$ \\
\hline
\end{tabular}

후 물체 $\mathrm{A}$ 의 각속도는 거의 변화가 없음을 알 수 있다. 이 그림들에는 참고문헌 4 의 결과와 비 교하여 본 논문의 결과의 정확도를 검증하였다. Figure 5와 6에는 분리 전 물체 $\mathrm{A}$ 와 $\mathrm{B}$ 사이에 작용하는 구속력과 구속모멘트를 나타낸다.

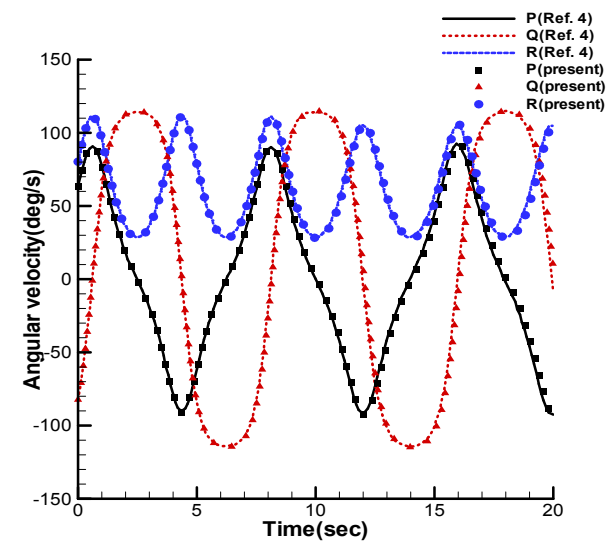

Fig. 3. Angular Velocity of Body A

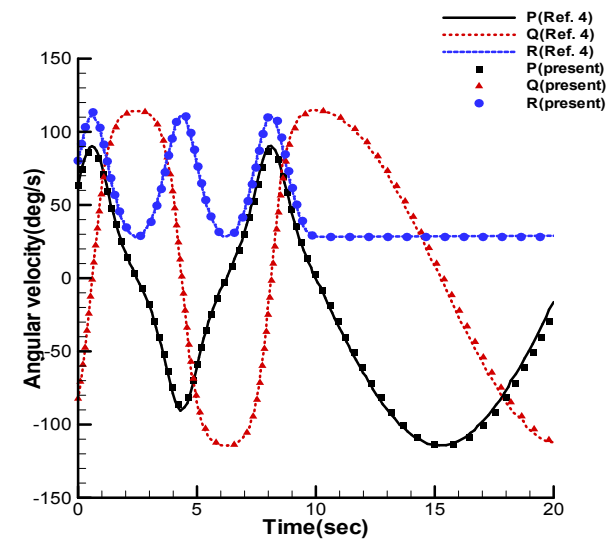

Fig. 4. Angular Velocity of Body B

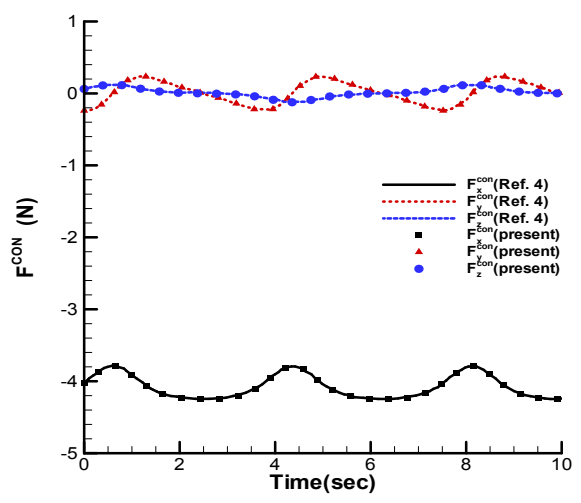

Fig. 5. Constraint Force 


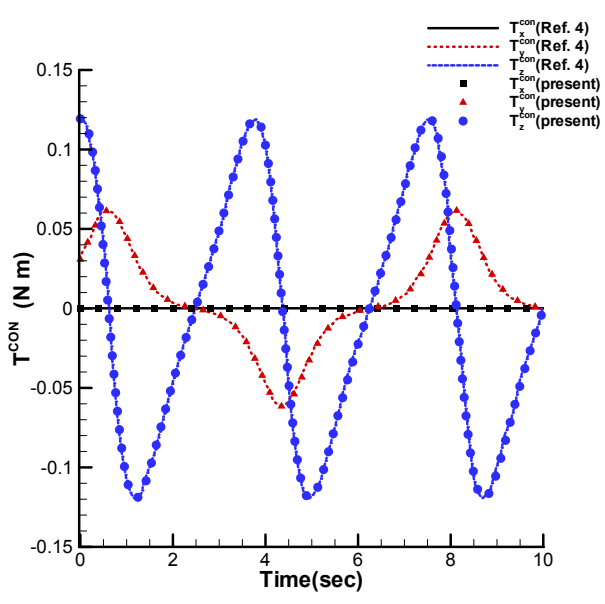

Fig. 6. Constraint Moment

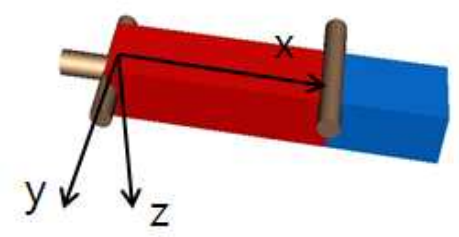

Fig. 7. Double Pendulum

Table 3. Mass property of Double Pendulum

\begin{tabular}{c|c|c}
\hline & Body A & Body B \\
\hline 질량 & $3900 \mathrm{~kg}$ & $1950 \mathrm{~kg}$ \\
$I_{x x}$ & $162.5 \mathrm{~kg} \mathrm{~m}^{2}$ & $81.25 \mathrm{~kg} \mathrm{~m}^{2}$ \\
$I_{y y}$ & $1381.25 \mathrm{~kg} \mathrm{~m}^{2}$ & $203.125 \mathrm{~kg} \mathrm{~m}^{2}$ \\
$I_{z z}$ & $1381.25 \mathrm{~kg} \mathrm{~m}^{2}$ & $203.125 \mathrm{~kg} \mathrm{~m}^{2}$ \\
\hline
\end{tabular}

\subsection{Double pendulum}

Figure 7에는 만능조인트와 회전조인트로 고정 되어 있는 물체 $\mathrm{A}$ 와 $\mathrm{B}$ 를 도시하였다. 물체 $\mathrm{A}$ 와 $\mathrm{B}$ 의 가로, 세로는 모두 $0.5 \mathrm{~m}$ 이다. 그러나 물체 $\mathrm{A}$ 의 길이는 $2 \mathrm{~m}$ 이고 물체 $\mathrm{B}$ 의 길이는 $1 \mathrm{~m}$ 다. 물 체 $\mathrm{A}$ 는 관성좌표계의 원점과 만능조인트로 접촉 되어 $x$ 축과 $y$ 축을 따라 회전하고, 물체 $\mathrm{A}$ 와 $\mathrm{B}$ 는 한 모서리가 회전조인트로 접촉되어 있다. 그리 고 물체 $\mathrm{A}$ 와 물체 $\mathrm{B}$ 가 중력가속도에 의해서 선 속도가 없이 관성좌표계의 원점을 중심으로 각속 도 $45 \hat{i}+0 \hat{j}+0 \hat{k}\left({ }^{\circ} / s\right)$ 로 회전운동을 한다. 이 문 제는 3 개 물체의 운동을 고려함으로써 해석하였 다. 물체 $\mathrm{O}$ 의 운동을 완전히 구속하여 운동이 발 생하지 않도록 하였다.

Figure 8과 9에는 물체 $\mathrm{A}$ 와 물체 $\mathrm{B}$ 의 이동거

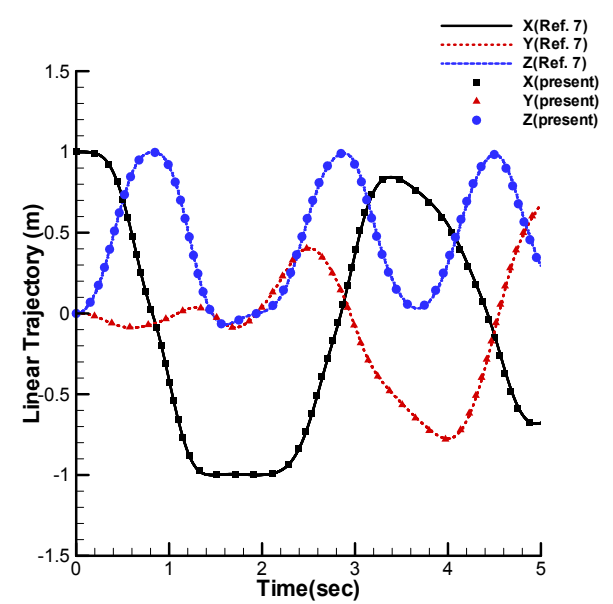

Fig. 8. Linear Trajectory of Body A

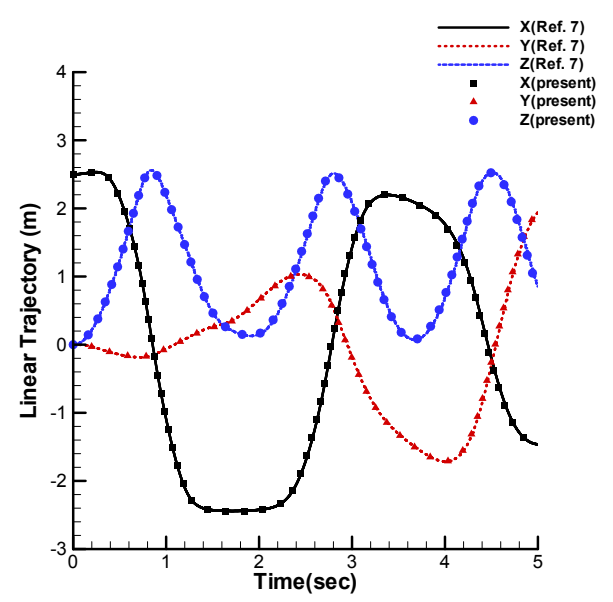

Fig. 9. Linear Trajectory of Body B

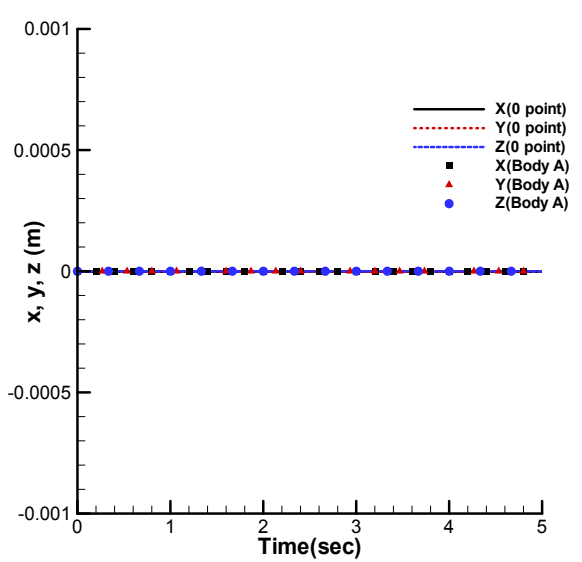

Fig. 10. Contact Point of Body 0 and $A$ 


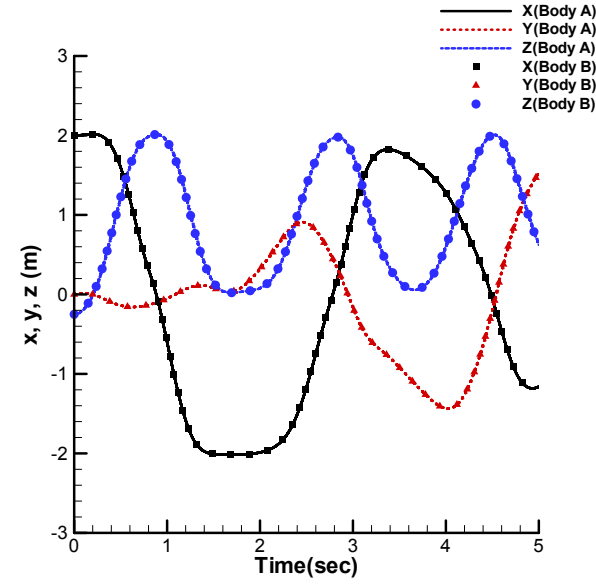

Fig. 11. Contact Point of Body A and B

리이다. 이 그림에는 상용 다물체 동역학 해석 프로그램인 Universal Mechanism[7]의 결과와 비교하여 본 논문의 결과의 정확도를 검증하였 다. 물체 $\mathrm{A}$ 와 물체 $\mathrm{B}$ 모두 $x$ 축과 $z$ 축 방향으로 크기만 다를 뿐 같은 형태의 운동을 한 것을 확 인할 수 있다. 또한, $x$ 축을 따라서 회전운동이 일어나므로 $y$ 축 방향 이동거리는 계속 증가하는 것을 확인할 수 있다. 그리고 물체 0 과 물체 $\mathrm{A}$ 의 시간에 따른 접촉점의 위치 변화와 물체 $\mathrm{A}$ 와 물 체 $\mathrm{B}$ 의 시간에 따른 접촉점의 위치 변화는 Fig. 10,11 에 도시하였다. 물체 0 과 물체 $\mathrm{A}$ 의 접촉점 은 원점으로 일정한 것을 확인할 수 있고, 물체 $\mathrm{A}$ 와 물체 $\mathrm{B}$ 의 접촉점은 서로 같은 위치로 움직 이고 있는 것을 확인할 수 있다. 그러므로 구속 조건이 만족함을 알 수 있다. 이를 통해서 2 개의 물체뿐만 아니라 3 개의 물체가 서로 다른 구속조 건으로 연결되어 있는 다물체 운동해석에도 사용 될 수 있는 것을 확인할 수 있다.

\subsection{Store separation}

Figure 12와 같이 외부장착물이 파일론(pylon) 에 고정되어 있다가 앞에 있는 후크(hook)가 분 리가 되면 외부장착물이 뒤에 있는 피벗(pivot)을 중심으로 회전운동을 한다. 그리고 외부장착물와 파일론이 이루는 각도가 10 도가 되었을 때 뒤에 있는 비벗도 분리가 되어 자유낙하하게 된다. $x$ 축이 외부장착물의 전두부를 향하는 방향이고, $z$ 축은 지면을 향하는 방향으로 하였다.

서론에서도 언급하였듯이 본 계산에는 공기력 의 영향을 고려하지 않았다. Fig. 13과 14는 외부 장착물의 무게중심의 이동거리와 각도를 나타낸 것이다. 또한 이 그림에는 비교를 위하여 참고

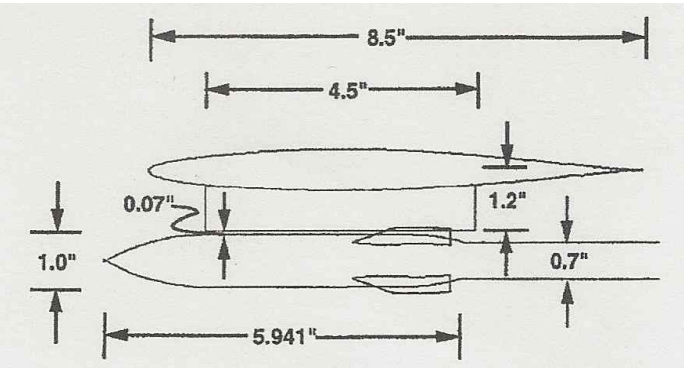

Fig. 12. Configuration of Wing and Store

Table 3. Mass property of store

\begin{tabular}{c|c}
\hline & Body \\
\hline 질량 & $907.1848 \mathrm{~kg}$ \\
$I_{x x}$ & $27.1164 \mathrm{~kg} \mathrm{~m}^{2}$ \\
$I_{y y}$ & $488.0944 \mathrm{~kg} \mathrm{~m}^{2}$ \\
$I_{z z}$ & $488.0944 \mathrm{~kg} \mathrm{~m}^{2}$ \\
\hline
\end{tabular}

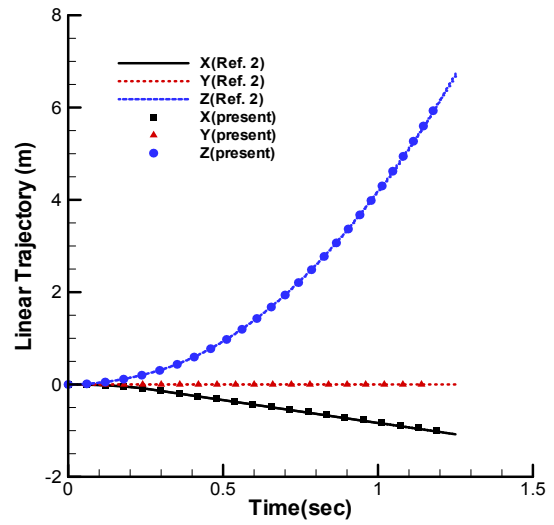

Fig. 13. Linear Trajectory

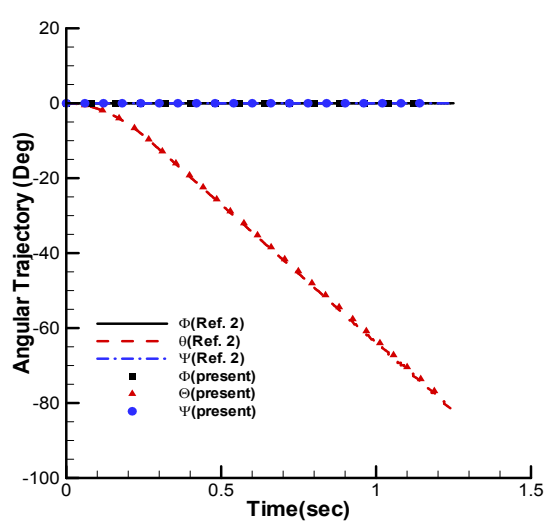

Fig. 14. Angular Trajectory 
문헌 [2]의 해석결과도 같이 도시하였다. Fig. 14 를 보면 0.27 초까지 피치각, $\theta$ 이 포물선으로 증가 하다 0.27 초 후에 직선으로 증가하는 것을 보고 외부장착물은 약 0.27 초까지 회전운동을 한 후 텀블링 운동을 하면서 자유낙하하는 것을 확인할 수 있었다. 그리고 $y$ 축을 중심으로 회전하기 때 문에 $y$ 축 방향으로 이동이 일어나지 않았으며, $\Phi$ 와 $\Psi$ 도 0 으로 일정한 것을 확인할 수 있다.

\section{IV. 결 론}

다양한 분리 시나리오에 따른 외부장착물의 분리해석을 위하여 7 가지 조인트 모델을 갖는 다 물체 운동해석 프로그램을 개발하였다. 본 논문 에서는 7 가지 조인트 모델 중 고정조인트, 회전 조인트와 만능조인트를 갖는 다물체의 운동해석 을 통해서 프로그램의 정확성을 검증하였다. 또 한, 회전조인트를 이용한 무장분리 해석을 하였 다. 개발된 프로그램을 이용하면 구속조건이 있 는 외부장착물의 분리해석이 가능함을 보였다. 개발된 프로그램은 외부장착물 분리해석 프로그 램에 접목될 예정이다.

\section{참고문헌}

1) 곽인근, 신재화, 이승수, 최기영, 현재수, 김 남균, “외부 장착물 분리 해석을 위한 Off-line 6-DOF 시뮬레이션 프로그램 개발", 한국항공우 주학회지, 제 37권 12호, 2009, pp. .

2) 신재화, 정재훈, 이승수, 최기영, 김상호, 현
재수, 김남균, 이종국, "Generalized Force 기반의 장착물 분리 시험 시스템 운동방정식 구성", 한 국항공우주학회 2009년도 춘계학술대회논문집, 2007.

3) 김병규, 이승수, 김상진, 강인모, 김명성, "날개 전개가 가능한 무장의 분리 특성해석", 한 국항공우주학회지, 제 25권 5호, 2007.

4) Magdi Rizk and Jae M. Lee, "Beggar code Implementation of the $(6+)$ DOF Capability for Stores with Moving Components", AIAA paper 2004-1251, 2004.

5) Paul V. Tartabini, Carlos Roithmayr, Matthew D. Tomiolo, Christopher Karlgaard, Bandu N. Pamadi, "Verification of the Constraint Force Equation Methodology for Modeling Multibody Stage Separation", AIAA paper 2008-7039, 2008.

6) Matthew D. Tomiolo, Paul V. Tartabini, Bandu N. Pamadi, Nathaniel Hotchko, "Constraint Force Equation Methodology for Modeling Multi-body Stage Separation Dynamics", AIAA paper 2008-219, 2008.

7) http://www.umlab.ru/index.htm.

8) 박선호, CFEM을 이용한 구속조건이 있는 다물체 운동해석, 석사학위논문, 인하대학교, 2011.

9) Lawrence E. Lijewski and Norman E. Suhs, "Time-Accurate Computational Fluid Dynamics Approach to Transonic Store Separation Trajectory Prediction", Journal of Aircraft, Vol. 31, No. 4, 1994. 